\title{
Survey of Crimean-Congo Hemorrhagic Fever Enzootic Focus, Spain, 2011-2015
}

\author{
Ana Negredo, Miguel Ángel Habela, Eva Ramírez de Arellano, Francisco Diez, \\ Fátima Lasala, Pablo López, Ana Sarriá, Nuria Labiod, Rafael Calero-Bernal, Miguel Arenas, \\ Antonio Tenorio, Agustín Estrada-Peña, Maria Paz Sánchez-Seco
}

During 2011-2015, we conducted a Crimean-Congo hemorrhagic fever virus (CCHFV) survey in captured ticks that were feeding mainly on wild and domestic ungulates in Spain, where presence of this virus had been reported previously. We detected CCHFV RNA in Hyalomma lusitanicum and $H$. marginatum ticks for 3 of the 5 years. The rate of infected ticks was $2.78 \%(44 / 1,579)$, which was similar to those for other countries in Europe with endemic foci for CCHFV (Kosovo, Bulgaria, and Albania). These data confirm the established spread of CCHFV into western Europe. Phylogenetic study of the small RNA segment showed Africa-3 clade as the only genotype identified, although we observed cocirculation of genetic variants during 2011 and 2015. We could not rule out genetic reassortments because of lack of sequence data for the medium and large RNA segments of the virus genome.

O rimean-Congo hemorrhagic fever virus (CCHFV), an RNA virus of the family Nairoviridae, is the most widespread tickborne virus affecting humans. It causes Crimean-Congo hemorrhagic fever (CCHF), which has a high mortality rate in humans (1) in many countries in Asia, the Middle East, eastern Asia, Africa, and Europe $(2,3)$. Recently, CCHF has been detected in Spain, indicating its spread into western Europe $(4,5)$.

$\mathrm{CCHF}$ is a zoonosis maintained between ticks and vertebrate animals. Ticks are both the vector and the natural reservoir of CCHFV. Ticks transmit CCHFV to large and small mammals, which act as amplifier hosts without signs of illness. Birds are predominantly refractory to CCHFV infection (6-8). The virus has been isolated from several Author affiliations: National Center of Microbiology, Madrid, Spain (A. Negredo, E. Ramírez de Arellano, F. Diez, F. Lasala,

P. López, N. Labiod, A. Tenorio, M.P. Sánchez-Seco); University of Extremadura, Cáceres, Spain (M.Á. Habela, R. Calero-Bernal); La Paz Hospital, Madrid (A. Sarriá); University of Vigo,

Pontevedra, Spain (M. Arenas); University of Zaragoza, Zaragoza, Spain (A. Estrada-Peña)

DOI: https://doi.org/10.3201/eid2506.180877 genera and species of ixodid ticks (9). However, most data are for ticks collected while feeding, a method that provides an unrealistic view of the actual species vectors (10).

The main vectors involved in CCHFV transmission are ticks of the genus Hyalomma (11-14). Immature ticks acquire the virus by feeding on infected small vertebrates or by the transovarial route. Once infected, they remain infected throughout their development and, when they are mature, transmit the infection to large animals, such as livestock. Transovarian and venereal transmission pathways have also been demonstrated (2). Another transmission mechanism is co-feeding, which results from spreading of the virus in tick saliva directly to other ticks feeding nearby (13).

In disease-endemic areas, CCHF is sporadic and is transmitted to humans by tick bites or contact with viremic animals or humans and occurs mainly in remote or agricultural regions (15-21). CCHF is seasonal in association with the life cycle and activity levels of local tick populations. CCHF outbreaks and nosocomial transmission has also been reported most often when an infectious case is not suspected early enough to permit use of proper containment protocols (22). Persons at risk are most frequently found among farmers and their families, as well as slaughterhouse and healthcare workers, veterinarians, and military personnel (23).

Only 2 autochthonous human cases of CCHF have been reported in Spain in an episode with tick and nosocomial transmission. The cases occurred in 2016, and the viruses isolated from these patients were included in the Africa-3 clade (genotype III) $(5,24)$, the same clade that was found in local ticks $(4,25)$ and 1 of the $6 / 7$ genetic clades in which CCHFV strains are grouped on the basis of small (S) RNA segment sequence homology $(26,27)$. Previously, the CCHFV genome was detected in ticks collected in 2010 from red deer in Cáceres, Spain (4), which is $300 \mathrm{~km}$ from the area (Ávila Province) where the index case-patient acquired the disease through tick bite transmission. After autochthonous human cases were detected, 
a surveillance study on ticks was conducted to investigate the spread of CCHFV in Spain. Results showed 4 geographic regions with CCHFV-positive results (Figure 1) and the presence of CCHFV in 128 (3.2\%) of 3,959 pools of ticks collected from wild and domestic animals (28). All CCHFV-positive ticks were collected while they were feeding on wild animals.

These data highlighted the emerging threat for CCHF in Spain and potentially all of western Europe. A new case of CCHF also linked to tick bite transmission occurred in August 2018 in Spain. A study of the presence of CCHFV in Spain was initiated in 2011 to analyze principally its circulation in the region of original detection. We report the results of a survey covering 5 years of collection.

\section{Materials and Methods}

\section{Study Area and Tick Collections}

Tick collection in Cáceres Province (southwestern Spain, $37^{\circ} \mathrm{N}-41^{\circ} \mathrm{N}, 3^{\circ} \mathrm{W}-7^{\circ} \mathrm{W}$ ) (Figure 1) was focused on adult ticks infesting red deer (Cervus elaphus) and, to a lesser extent, other mammals, such as fallow deer (Dama dama), red foxes (Vulpes vulpes), and wild boars (Sus scrofa ferus), legally hunted in privately owned estates during October-February. Sampling areas are located within typical Mediterranean Quercus forest in several protected areas and reserves (Tajo International Natural Park and Sierra de San Pedro Mountain Range), which constitute an optimum ecosystem for wild ungulates. Collection of ticks from cattle was also conducted in Cáceres Province. We directly shipped ticks collected at room temperature to the Parasitology Laboratory of the Faculty of Veterinary Medicine at the University of Extremadura (Cáceres). Ticks were identified to species within 1-2 days upon arrival, and frozen at $-65^{\circ} \mathrm{C}$ while alive until isolation of RNA. Tick collection in Segovia Province $\left(41.21^{\circ} \mathrm{N}, 3.59^{\circ} \mathrm{W}\right)$ was conducted during the sheep shearing process, and adult ticks captured were identified in the Spanish National Center of Microbiology. Tick collections on the ground were also performed in $\mathrm{Hu}-$ esca $\left(42.21^{\circ} \mathrm{N}, 0.13^{\circ} \mathrm{W}\right)$ and Toledo $\left(39.23^{\circ} \mathrm{N}, 4.29^{\circ} \mathrm{W}\right)$ Provinces. We captured mainly adult ticks and identified them in the Animal Pathology Department of the Faculty of Veterinary Medicine at the University of Zaragoza. All ticks were sent in dry ice to the Spanish National Center of Microbiology (Madrid, Spain) for processing.

\section{Extraction of RNA from Tick Species}

Ticks were washed twice with water and once with ethanol and then individually crushed by using a plastic homogenizer in $500 \mu \mathrm{L}$ AVL buffer (QIAGEN, https://www. qiagen.com). We conducted homogenization in a Biosafety Level-3 laboratory. After homogenization, we stored 250

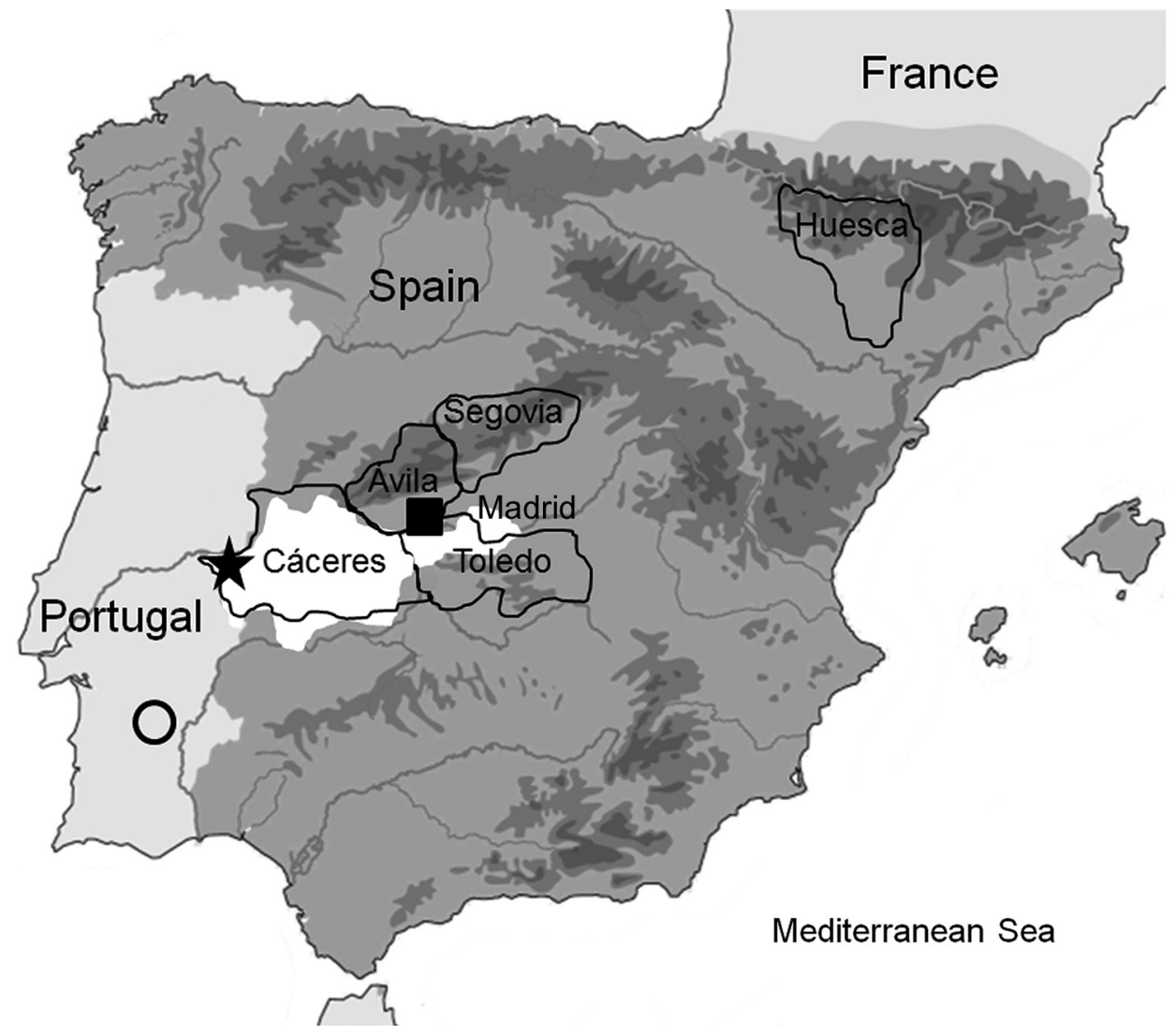

Figure 1. Study site locations in the Iberian Peninsula in which Crimean-Congo hemorrhagic fever virus was detected: Cáceres, Toledo, Segovia, and Huesca Provinces. Square shows presence of CCHFV in humans bitten by a tick, star shows presence of CCHFV in ticks with positive results by PCR, circle indicates region where serum samples positive for CCHFV were detected in Portugal, and white area shows regions in 4 localities (Cáceres, Ávila, and Toledo Provinces and Madrid) in Spain where CCHFVpositive ticks had been previously identified. 
$\mu \mathrm{L}$ of the sample in AVL buffer at $-80^{\circ} \mathrm{C}$ and used $250 \mu \mathrm{L}$ for total extraction of RNA with the QIAamp Viral RNA Mini Kit (QIAGEN), according to the recommendations of the manufacturer. RNA was eluted in $60 \mu \mathrm{L}$ of RNAasefree water and stored at $-80^{\circ} \mathrm{C}$ until needed.

\section{Reverse Transcription PCR}

We used an in-house nested reverse transcription PCR specific for the S genome segment (5). We individually analyzed ticks.

\section{DNA Sequencing}

We purified amplified DNA by using an Illustra ExoProStar Kit (GE Healthcare Life Sciences, https://www.gelifesciences.com). We sequenced double-stranded DNA directly by using the Sanger chain-termination method and the BigDye Terminator v3.1 Cycle Sequencing Kit Protocol and the ABI PRISM 3700 DNA Analyzer (Applied Biosystems, https:// www.thermofisher.com). We used sequencing primers $\mathrm{Cr}$ Con2+ and CrCon2-, the same used in the nested PCR (5). We assembled consensus sequences of each segment and analyzed them by using the SeqMan Program in the Lasergene Package (https://www.dnastar.com).

\section{Phylogenetic Analysis}

We aligned nucleotide sequences by using Muscle in MEGA version 7 (https://www.megasoftware.net). Because recombination can bias phylogenetic tree reconstruction, we analyzed recombination in the alignment with the Recombination Detection Program (http://web.cbio.uct. ac.za/ darren/rdp.html) and the Hypothesis Testing Using Phylogenies Program (http://hyphy.org). We did not detect genetic signatures of recombination.

We generated a maximum clade credibility (MCC) genealogy by using BEAUTi and BEAST (29). We ran the Markov chain Monte Carlo method for 100 million generations, sampling every 1,000 steps, and analyzed convergence with Tracer (http://www.beast2.org) to ensure that effective sample sizes were $>200$. We applied the uncorrelated lognormal clock model, the general timereversible matrix with gamma distribution and proportion of invariable sites substitution model, and the exponential tree prior. We summarized reconstructed trees by applying the MCC approach implemented in TreeAnnotator version 1.8 .4 (http://beast.community/treeannotator), used the mean value as the node height, and discarded the first $10 \%$ of the generated trees as burn-in. We visualized the MCC tree by using FigTree version 1.4.3 (http:// tree.bio.ed.ac.uk). We deposited nucleotide sequences with lengths $>200 \mathrm{nt}$ obtained with primers CrCon1+ and CrCon 1- (5) in the European Molecular Biology Laboratory/GenBank databases (accession nos. MH337845 and MH337846).

\section{Results}

We collected 1,579 ticks in 4 geographic regions in Spain (Figure 1), 206 from vegetation and 1,373 from animals. Of ticks collected from animals, 1,329 (96.79\%) were from wild animals and $44(3.35 \%)$ were from domestic animals.

Collected ticks that we could identify belonged to 1 of 4 genera: Rhipicephalus (46, 2.91\%), Hyalomma $(1,317,83.40 \%)$, Dermacentor $(1,0.06 \%)$, or Ixodes $(3,0.18 \%) ; 212$ ticks could not be identified. Most ticks were $H$. lusitanicum $(1,079,68.33 \%)$ and $H$. marginatum $(238,15.07 \%)$ (Table). H. lusitanicum ticks were obtained mainly from wild animals $(1,063 / 1,329)$, and H. marginatum ticks $(206 / 238)$ were collected principally from vegetation.

We detected CCHFV RNA in $44(2.78 \%)$ of 1,579 ticks collected (Table). All CCHFV-positive ticks were detected in Cáceres $(3.25 \%$; 44/1,352). We collected ticks in 31 localities within Cáceres; 5 (16.12\%) localities (1, 2, 23, 27, and 28) had virus-positive ticks. Rates for CCHVpositive ticks were $8.79 \%$ in locality $1,9.03 \%$ in locality $2,7.14 \%$ in locality $23,2.77 \%$ in locality 27 , and $2.22 \%$ in locality 28. CCHFV-positive ticks were collected during 2011, 2013, and 2015. In Cáceres, the rate of CCH$\mathrm{FV}$ in ticks was $4.1 \%$ in $2011,6.4 \%$ in 2013 , and $3.42 \%$ in 2015 .

A total of $43 \mathrm{H}$. lusitanicum ticks and $1 \mathrm{H}$. marginatum tick were positive for CCHFV (Table); 41 of 43 CCHFV-positive $H$. lusitanicum ticks were collected while feeding on red deer, and CCHFV-positive H. marginatum ticks were collected from 1/6 bovine animals analyzed in locality 23 (Table). Six H. lusitanicum ticks and $1 \mathrm{H}$. marginatum tick were found on this animal. Of these ticks, $1 \mathrm{H}$. lusitanicum male and $1 \mathrm{H}$. marginatum female were positive for CCHFV. This animal might not have been viremic, which would explain why only 2 of 6 ticks were infected by the co-feeding transmission mechanism, in which virus present in tick saliva can spread directly to other ticks feeding nearby. In locality number 23, CCHFV-positive $H$. lusitanicum ticks were detected on a second cow and 1 red deer.

We obtained sequences from 43 of 44 CCHFV-positive ticks. CCHFV sequences from Spain had the highest identities (90.6\%-99.6\%) with the Sudan AB-1-2009 strain in the analyzed fragment of the S RNA segment.

Phylogenetic analyses based on a 175-bp fragment of the S RNA segment separated CCHFV into 7 well-supported groups in association with the geographic distribution Asia 1, Asia 2, Africa 1-3, and Europe 1 and 2. All sequences grouped with clade Africa-3 (genotype III) viruses from South Africa and West Africa (Figure 2) and showed 4 groups with identities of $100 \%$. One group (A) was formed by 4 sequences, the second group (B) by 12 , the third group (C) by 24 , and the fourth group (D) by 4 . 
For each group, the percentage of diversity was $0.07 \%-$ $0.09 \%$. Bayesian analysis showed that the estimated time to the most recent common ancestor (tMRCA) of lineage A was $\approx 1979$ (95\% highest posterior density [HPD] 1968-1984), which diverged before lineages B (1999;
95\% HPD, 1986-2009), C (2004; 95\% HPD, 1992-2014), and D (1996; HPD 1973-2013). Use of the 175-nt fragment to calculate the tMRCA of lineage A was supported by results reported by Cajimat et al. (25), who used the complete S segment (1965; 95\% HPD 1948-1980).

\begin{tabular}{|c|c|c|c|c|c|}
\hline Year (no. ticks) & Province (no. ticks) & $\begin{array}{l}\text { Sampling } \\
\text { site }\end{array}$ & $\begin{array}{l}\text { Collection site } \\
\text { or host }\end{array}$ & Tick species & $\begin{array}{l}\text { No. positive ticks/ } \\
\text { wno. tested (\%) }\end{array}$ \\
\hline \multirow[t]{13}{*}{$2011(474)$} & Toledo $(78)$ & 31 & Ground & Hyalomma marginatum & $0 / 78$ \\
\hline & $\begin{array}{l}\text { Huesca (128) } \\
\text { Cáceres (268) }\end{array}$ & 32 & Ground & H. marginatum & $0 / 128$ \\
\hline & & 1 & Deer & H. Iusitanicum & $8 / 139(5.75)$ \\
\hline & & 2 & Deer & H. Iusitanicum & $3 / 35(8.57)$ \\
\hline & & 3 & Deer & H. marginatum & $0 / 4$ \\
\hline & & 4 & Deer & Unknown & $0 / 20$ \\
\hline & & 5 & Red fox & Unknown & $0 / 3$ \\
\hline & & 6 & Cattle & Unknown & $0 / 2$ \\
\hline & & 7 & Deer & H. Iusitanicum & $0 / 24$ \\
\hline & & 8 & Deer & Unknown & $0 / 3$ \\
\hline & & 9 & Deer & Unknown & $0 / 7$ \\
\hline & & 10 & Deer & Unknown & $0 / 20$ \\
\hline & & 11 & Deer & Rhipicephalus bursa nymphs & $0 / 11$ \\
\hline \multirow[t]{2}{*}{$2012(48)$} & Cáceres (27) & 1 & Deer & H. Iusitanicum & $0 / 27$ \\
\hline & Segovia (21) & 33 & Cattle/sheep & Rhipicephalus sp. & $0 / 21$ \\
\hline \multirow[t]{9}{*}{$2013(201)$} & Cáceres (201) & & & & \\
\hline & & 1 & Deer & H. Iusitanicum & $13 / 68(19.11)$ \\
\hline & & 2 & Deer & Unknown & $0 / 5$ \\
\hline & & 10 & Deer & H. Iusitanicum & $0 / 53$ \\
\hline & & 12 & Deer & H. Iusitanicum & $0 / 24$ \\
\hline & & 13 & Deer & R. bursa & $0 / 5$ \\
\hline & & 14 & Deer & H. marginatum & $0 / 23$ \\
\hline & & 15 & Deer & Unknown & $0 / 6$ \\
\hline & & 16 & Deer & Unknown & $0 / 17$ \\
\hline \multirow[t]{11}{*}{$2014(272)$} & Cáceres (272) & & & & \\
\hline & & 1 & Deer & H. Iusitanicum & $0 / 57$ \\
\hline & & 4 & Deer & Unknown & $0 / 41$ \\
\hline & & 15 & Deer & Unknown & $0 / 17$ \\
\hline & & 17 & Deer and wild boar & Unknown & $0 / 18$ \\
\hline & & 18 & Deer and wild boar & H. Iusitanicum & $0 / 20$ \\
\hline & & 19 & Deer & Unknown & $0 / 31$ \\
\hline & & 20 & Deer & H. Iusitanicum & $0 / 35$ \\
\hline & & 21 & Deer and wild boar & Unknown & $0 / 19$ \\
\hline & & 22 & Deer & H. Iusitanicum & $0 / 18$ \\
\hline & & 23 & Deer & H. Iusitanicum & $0 / 16$ \\
\hline \multirow[t]{15}{*}{$2015(584)$} & Cáceres (584) & & & & \\
\hline & & 1 & Deer & H. Iusitanicum & $3 / 66$ (4.54) \\
\hline & & 2 & Deer & H. Iusitanicum & $11 / 120(9.16)$ \\
\hline & & 4 & Deer & H. Iusitanicum & $0 / 25$ \\
\hline & & 18 & Deer & H. Iusitanicum & $0 / 40$ \\
\hline & & 19 & Deer & 30 H. lusitanicum, 1 R. bursa & $0 / 31$ \\
\hline & & 23 & Deer & $34 \mathrm{H}$. Iusitanicum, 1 Ixodes ricinus & $1 / 35(2.85)$ \\
\hline & & & Cattle & $\begin{array}{c}16 \mathrm{H} . \text { lusitanicum, } \\
5 \mathrm{H} . \text { marginatum }\end{array}$ & $3 / 21(14.28)$ \\
\hline & & 24 & Deer & $\begin{array}{c}14 \text { H. Iusitanicum, } 8 \text { R.bursa, } \\
1 \text { Dermacentor sp. }\end{array}$ & $0 / 23$ \\
\hline & & 25 & Fallow deer & $\begin{array}{l}6 \text { H. Iusitanicum, } 2 \text { I. ricinus. } \\
3 \text { unknown }\end{array}$ & $0 / 11$ \\
\hline & & 26 & Deer & H lusitanicum & 0/32 \\
\hline & & 27 & Deer & H. Iusitanicum & $1 / 36(2.77)$ \\
\hline & & 28 & Deer & H. Iusitanicum & $1 / 45(2.22)$ \\
\hline & & 29 & Deer & H. Iusitanicum & 0/72 \\
\hline & & 30 & Deer & H. Iusitanicum & $0 / 27$ \\
\hline Total & & & 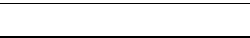 & 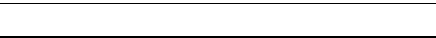 & $44 / 1579(2.78)$ \\
\hline
\end{tabular}




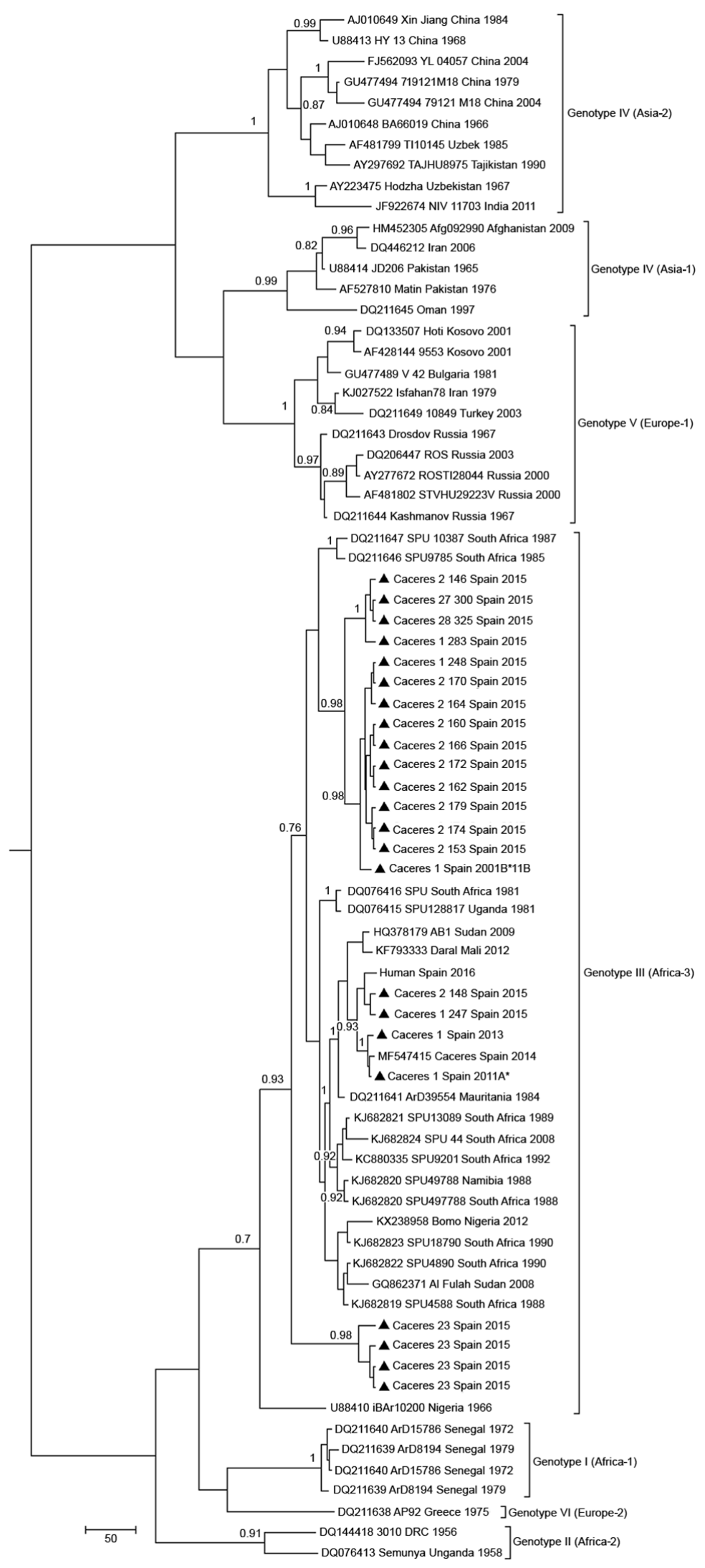

Figure 2. Maximum clade credibility genealogy based on partial (175-nt) sequences of the CrimeanCongo hemorrhagic fever virus small RNA segment of viruses from Spain and reference sequences. Numbers along branches indicate posterior probability values for the groups (values $<0.70$ are not shown). Triangles indicate newly sequenced strains from Spain reported in this study, which are identified by geographic origin, sampling site, and sampling year. Other sequences are indicated by GenBank accession number, strain, geographic origin, and sampling year. Sequences from this study indicated with an asterisk are included in European Molecular Biology Laboratory/GenBank databases. Genotypes are indicated in roman numerals and named according to Carroll et al. (30). Equivalent clade nomenclature is listed according to Chamberlain et al. (31) and indicated at right. Scale bar indicates nucleotide substitutions per site. 


\section{Discussion}

An ongoing surveillance study of CCHFV in ticks was conducted because this virus was detected in Spain in 2010 (4). Thus, ticks were collected during 2011-2015, mainly in wild animals in the region where CCHFV was detected (Cáceres) and also in other regions (Huesca and Toledo) that are colonized by Hyalomma spp., or that have an abundance of domestic ungulates (Segovia). We detected $\mathrm{CCH}-$ $\mathrm{FV}$ in Cáceres in 3 of the 5 years, indicating the resilience of a CCHFV focus in Spain and confirming the established spread of CCHFV into western Europe.

The rate of CCHFV-infected ticks determined in this study $(2.78 \%, 44 / 1,579)$ was similar to those for other countries in Europe that have enzoonotic foci, such as Kosovo $(3.6 \%$, 40/1,102) (12), Bulgaria (2\%-4.83\%) (32), and Albania (3\%) (23). Despite these data, no human cases were documented in Spain during the years of the study. This situation shows that human cases probably occur rarely, even though the virus is quite active in hostseeking ticks in the area. We detected CCHFV in Hyalomma ticks collected on cattle and deer in Cáceres in 5 of 31 hunting areas, 2 of which have repeatedly been found to be positive for CCHFV. In the maintenance of active CCHFV foci, habitat fragmentation, such as in the Cáceres region studied, might lead to isolated populations of ticks and hosts producing an amplification cycle in which ticks feed on infected hosts (33). However, birds carrying infected ticks on their surface or infected small mammals, such as brown hares and rabbits, can spread the virus to new areas. In August 2016, in a rural area of Ávila, Spain (Figure 1), where no evidence of CCHFV circulation was previously described and that is $300 \mathrm{~km}$ from the CCHFV enzoonotic focus in Cáceres, a human infection occurred after a tick bite (5).

Our study spanned 5 years; virus was detected during 2011, 2013, and 2015. In 2012, the number of samples collected was low. During 2014, our laboratory obtained 2 CCHFV-positive ticks that had low viral loads that could not be confirmed, although virus circulation during that year in Cáceres was demonstrated by Cajimat et al. (25). This finding reflects intermittent activity of the CCHFV foci in Cáceres, which becomes periodically apparent as described in other countries $(13,34)$. In southern Portugal, which is close to this region (Figure 1), antibodies against this virus were detected in 2 human serum samples during 1980 (35), suggesting silent circulation of the virus in the Iberian Peninsula. Introduction of the virus into Spain has been calculated to have occurred $\approx 50$ years ago $(25)$, which was corroborated by our study.

In our study, of the 4 genera of ticks collected, only Hyalomma ticks were found to harbor CCHFV (Table). All CCHFV-positive ticks were collected while feeding on ruminants, red deer, and cattle. All except 2 CCHFV- positive ticks, $1 \mathrm{H}$. lusitanicum and $1 \mathrm{H}$. marginatum, were collected on red deer. This finding confirmed that this tick-host relationship had a primary role in maintenance of CCHFV enzootic cycles in Spain and the role of red deer as a prominent host. The CCHFV-positive $H$. marginatum tick was collected from a cow along with an $H$. lusitanicum tick. Presumably, these ticks were infected by a co-feeding transmission mechanism in nonviremic animals because only 2 of 6 ticks feeding on the same animal were positive for CCHFV. Until now, CCHFV-positive H. marginatum ticks have not been detected in Spain, although this species is considered to be the main reservoir of CCHFV in Europe. This tick species can increase the risk for human cases of infection in Spain because of its proximity to human populations when compared with $H$. lusitanucum ticks. In addition, CCHFV-positive H. marginatum ticks have been captured in domestic animals that have close contact with humans. Previous studies in Spain that analyzed 2,500 ticks (28) and 1,408 ticks (36) collected from domestic ungulates did not report any CCHFV-infected ticks. Our results clearly show that the virus is active in the Cáceres region and that cattle might play a major role in transmission of the virus to new generations of ticks that could act as bridge vectors.

CCHFV sequences from Spain isolated during this study grouped with clade Africa-3. This clade contains strains separated by large spatial distances, mainly from Mauritania to Senegal, Nigeria, Sudan, and South Africa, suggesting that virus is most likely spread by migratory birds that transmit infected ticks or by secondary introductions after importation of commercial livestock. The presence of the Africa-3 clade in Europe must be considered because of the increased risk for its spread to other countries in Europe where Hyalomma ticks are present. In Greece, the Africa-3 clade was detected in ticks from migratory birds in the Greek archipelago (37), although this clade has not been detected in continental Greece. Virus sequences found in ticks in Spain are more closely related to CCHFV strains from central-northern Africa, a finding that supports the theory that the virus was spread northward by migrating birds. Moreover, the Africa-3 clade was detected recently in ticks from migratory birds in Morocco (38).

Although it is recognized that $175 \mathrm{nt}$ is a small genetic fragment for robust comparisons between closely related viruses, phylogenetic analyses of CCHFVs showed 4 well-supported clusters (with bootstrap values $>0.7$ and $p$ distances among clusters of $0.07 \%-0.09 \%$ ). We detected cocirculation of different clusters: 2 clusters during 2011 and 4 during 2015. Phylogenetic analysis showed that the tMRCA of the 4 CCHFV variants diverged to produce 2 lineages, 1 containing variants $\mathrm{A}, \mathrm{B}$, and $\mathrm{C}$ and the other containing variant $\mathrm{D}$. Whether this divergence occurred in Africa or in Spain cannot be determined with the limited 
sequence data currently available. The estimated tMRCA of lineage A was $\approx 1979$ and it diverged before lineages B (1999), C (2004), and D (1996). Use of the 175-nt fragment to estimate the tMRCA of lineage A is supported by results from another study (25), in which the complete S RNA segment was used (1965; 95\% HPD 1948-1980). Circulation of genetic variants of the same genotype could indicate multiple introductions of the virus or genetic evolution of a variant that has acted as an ancestor in autochthonous $H$. lusitanicum ticks in the Iberian Peninsula. Thus, adaptation of CCHFV to region-specific vectors and hosts leads to emergence of local virus variants as described recently in Kosovo (12). Genetic variability of these variants should be considered in molecular diagnostic methods (39).

The data obtained in this study, together with the CCHFV survey of ticks collected from animals conducted recently in Spain (28), as well as identification of 2 clinical cases caused by tick bites during 2016 and 2018 (5), show how the epidemiologic scenario of CCHF should include western Europe as an enzoonotic area and that surveillance studies on CCHFV in Spain and Portugal are necessary. Determining seroprevalence in animals and humans, as well as virus detection in ticks, would better define the risk for infection with CCHF in the Iberian Peninsula. These studies will help to determine the epidemiologic processes behind the known distribution of CCHFV in western Europe and establish adequate prevention and control measures to minimize the risk for cases of disease in Spain.

\section{Acknowledgments}

We thank Frank Hodgkins for reviewing the manuscript.

This study was supported by Instituto de Salud Carlos III (Projects RD12/0018/0006 and RD16CIII/0003/0003), Red de Enfermedades Tropicales Subprogram Redes Temáticas de Investigación Cooperativa en Salud Plan Estatal de I+D+I 2013-2016, Federación Española de Enfermedades Rares (Una Manera de Hacer Europa), and European Project EMERGE.

\section{About the Author}

Dr. Negredo is a senior researcher at the Arbovirus and Imported Viral Diseases Laboratory, National Center of Microbiology, Madrid, Spain. Her primary research interests are virus hemorrhagic fever and detection of emerging viruses that circulate in Spain.

\section{References}

1. World Health Organization. Crimean-Congo hemorrhagic fever. Fact sheet no. 208; 2013 [cited 2019 Mar 6]. http://www.who.int/ mediacentre/factsheets/fs208/en

2. Whitehouse CA. Crimean-Congo hemorrhagic fever. Antiviral Res. 2004;64:145-60. http://dx.doi.org/10.1016/j.antiviral.2004.08.001

3. Ergonul O. Crimean-Congo hemorrhagic fever virus: new outbreaks, new discoveries. Curr Opin Virol. 2012;2:215-20. http://dx.doi.org/10.1016/j.coviro.2012.03.001
4. Estrada-Peña A, Palomar AM, Santibáñez P, Sánchez N, Habela MA, Portillo A, et al. Crimean-Congo hemorrhagic fever virus in ticks, southwestern Europe, 2010. Emerg Infect Dis. 2012;18:179-80. http://dx.doi.org/10.3201/eid1801.111040

5. Negredo A, de la Calle-Prieto F, Palencia-Herrejón E, Mora-Rillo M, Astray-Mochales J, Sánchez-Seco MP, et al.; Crimean Congo Hemorrhagic Fever@Madrid Working Group. Autochthonous Crimean-Congo hemorrhagic fever in Spain. N Engl J Med. 2017;377:154-61. http://dx.doi.org/10.1056/ NEJMoa1615162

6. Hoogstraal H. The epidemiology of tick-borne Crimean-Congo hemorrhagic fever in Asia, Europe, and Africa. J Med Entomol. 1979;15:307-417. http://dx.doi.org/10.1093/jmedent/15.4.307

7. Gonzalez JP, Camicas JL, Cornet JP, Wilson ML. Biological and clinical responses of west African sheep to Crimean-Congo hemorrhagic fever virus experimental infection. Res Virol. 1998; 149:445-55. http://dx.doi.org/10.1016/S0923-2516(99)80013-2

8. Spengler JR, Estrada-Peña A, Garrison AR, Schmaljohn C, Spiropoulou CF, Bergeron É, et al. A chronological review of experimental infection studies of the role of wild animals and livestock in the maintenance and transmission of Crimean-Congo hemorrhagic fever virus. Antiviral Res. 2016;135:31-47. http://dx.doi.org/10.1016/j.antiviral.2016.09.013

9. Wasfi F, Dowall S, Ghabbari T, Bosworth A, Chakroun M, Varghese A, et al. Sero-epidemiological survey of Crimean-Congo hemorrhagic fever virus in Tunisia. Parasite. 2016;23:10. http://dx.doi.org/10.1051/parasite/2016010

10. Gargili A, Estrada-Peña A, Spengler JR, Lukashev A, Nuttall PA, Bente DA. The role of ticks in the maintenance and transmission of Crimean-Congo hemorrhagic fever virus: a review of published field and laboratory studies. Antiviral Res. 2017;144:93-119. http://dx.doi.org/10.1016/j.antiviral.2017.05.010

11. Gunes T, Poyraz O, Vatansever Z. Crimean-Congo hemorrhagic fever virus in ticks collected from humans, livestock, and picnic sites in the hyperendemic region of Turkey. Vector Borne Zoonotic Dis. 2011;11:1411-6. http://dx.doi.org/10.1089/ vbz.2011.0651

12. Sherifi K, Cadar D, Muji S, Robaj A, Ahmeti S, Jakupi X, et al. Crimean-Congo hemorrhagic fever virus clades V and VI (Europe 1 and 2) in ticks in Kosovo, 2012. PLoS Negl Trop Dis. 2014;8:e3168. http://dx.doi.org/10.1371/journal.pntd.0003168

13. Bente DA, Forrester NL, Watts DM, McAuley AJ, Whitehouse CA, Bray M. Crimean-Congo hemorrhagic fever: history, epidemiology, pathogenesis, clinical syndrome and genetic diversity. Antiviral Res. 2013;100:159-89. http://dx.doi.org/10.1016/j.antiviral.2013. 07.006

14. Spengler JR, Estrada-Peña A. Host preferences support the prominent role of Hyalomma ticks in the ecology of CrimeanCongo hemorrhagic fever. PLoS Neg1 Trop Dis. 2018;12:e006248. http://dx.doi.org/10.1371/journal.pntd.0006248

15. Papa A, Ma B, Kouidou S, Tang Q, Hang C, Antoniadis A. Genetic characterization of the M RNA segment of Crimean Congo hemorrhagic fever virus strains, China. Emerg Infect Dis. 2002;8:50-3. http://dx.doi.org/10.3201/eid0801.010087

16. Burt FJ, Swanepoel R. Molecular epidemiology of African and Asian Crimean-Congo hemorrhagic fever isolates. Epidemiol Infect. 2005;133:659-66. http://dx.doi.org/10.1017/ S0950268805003730

17. Christova I, Di Caro A, Papa A, Castilletti C, Andonova L, Kalvatchev N, et al. Crimean-Congo hemorrhagic fever, southwestern Bulgaria. Emerg Infect Dis. 2009;15:983-5. http://dx.doi.org/10.3201/eid1506.081567

18. Maltezou HC, Maltezos E, Papa A. Contact tracing and serosurvey among healthcare workers exposed to Crimean-Congo hemorrhagic fever in Greece. Scand J Infect Dis. 2009;41:877-80. http://dx.doi.org/10.3109/00365540903173619 
19. Mishra AC, Mehta M, Mourya DT, Gandhi S. Crimean-Congo hemorrhagic fever in India. Lancet. 2011;378:372. http://dx.doi.org/10.1016/S0140-6736(11)60680-6

20. Aradaib IE, Erickson BR, Karsany MS, Khristova ML, Elageb RM, Mohamed ME, et al. Multiple Crimean-Congo hemorrhagic fever virus strains are associated with disease outbreaks in Sudan, 2008-2009. PLoS Negl Trop Dis. 2011;5:e1159. http://dx.doi.org/ 10.1371/journal.pntd.0001159

21. Mustafa ML, Ayazi E, Mohareb E, Yingst S, Zayed A, Rossi CA, et al. Crimean-Congo hemorrhagic fever, Afghanistan, 2009. Emerg Infect Dis. 2011;17:1940-1. http://dx.doi.org/10.3201/ eid1710.110061

22. Nabeth P, Cheikh DO, Lo B, Faye O, Vall IO, Niang M, et al. Crimean-Congo hemorrhagic fever, Mauritania. Emerg Infect Dis. 2004;10:2143-9. http://dx.doi.org/10.3201/eid1012.040535

23. Papa A, Velo E, Papadimitriou E, Cahani G, Kota M, Bino S. Ecology of the Crimean-Congo hemorrhagic fever endemic area in Albania. Vector Borne Zoonotic Dis. 2009;9:713-6. http://dx.doi.org/10.1089/vbz.2008.0141

24. Ramírez de Arellano E, Hernández L, Goyanes MJ, Arsuaga M, Cruz AF, Negredo A, et al. Phylogenetic Characterization of Crimean-Congo Hemorrhagic fever virus, Spain. Emerg Infect Dis. 2017;23:2078-80. http://dx.doi.org/10.3201/eid2312.171002

25. Cajimat MN, Rodriguez SE, Schuster IU, Swetnam DM, Ksiazek TG, Habela MA, et al. Genomic characterization of Crimean-Congo hemorrhagic fever virus in Hyalomma tick from Spain, 2014. Vector Borne Zoonotic Dis. 2017;17:714-9. http://dx.doi.org/10.1089/vbz.2017.2190

26. Deyde VM, Khristova ML, Rollin PE, Ksiazek TG, Nichol ST. Crimean-Congo hemorrhagic fever virus genomics and global diversity. J Virol. 2006;80:8834-42. http://dx.doi.org/10.1128/ JVI.00752-06

27. Zehender G, Ebranati E, Shkjezi R, Papa A, Luzzago C, Gabanelli E, et al. Bayesian phylogeography of Crimean-Congo hemorrhagic fever virus in Europe. PLoS One. 2013;8:e79663. http://dx.doi.org/10.1371/journal.pone.0079663

28. de Sanidad M, Sociales e Igualdad S. Status report and assessment of the risk of transmission of Crimean-Congo hemorrhagic fever (FHCC) in Spain, April 2017 [in Spanish] [cited 2017 May 1]. http://www.msssi.gob.es/profesionales/saludPublica/ enfermedadesEmergentes/Crimea_Congo/docs/ ACTUALIZACION ER FHCC 20.04.2017.pdf

29. Drummond AJ, Suchard MA, Xie D, Rambaut A. Bayesian phylogenetics with BEAUti and the BEAST 1.7. Mol Biol Evol. 2012;29:1969-73. http://dx.doi.org/10.1093/molbev/mss075
30. Carroll SA, Bird BH, Rollin PE, Nichol ST. Ancient common ancestry of Crimean-Congo hemorrhagic fever virus. Mol Phylogenet Evol. 2010;55:1103-10. http://dx.doi.org/10.1016/ j.ympev.2010.01.006

31. Chamberlain J, Cook N, Lloyd G, Mioulet V, Tolley H, Hewson R. Co-evolutionary patterns of variation in small and large RNA segments of Crimean-Congo hemorrhagic fever virus. J Gen Virol. 2005;86:3337-41. http://dx.doi.org/10.1099/vir.0.81213-0

32. Gergova I, Kunchev M, Kamarinchev B. Crimean-Congo hemorrhagic fever virus tick survey in endemic areas in Bulgaria. J Med Virol. 2012;84:608-14. http://dx.doi.org/10.1002/ jmv. 23214

33. Estrada-Peña A, Vatansever Z, Gargili A, Ergönul O. The trend towards habitat fragmentation is the key factor driving the spread of Crimean-Congo hemorrhagic fever. Epidemiol Infect. 2010; 138:1194-203. http://dx.doi.org/10.1017/S0950268809991026

34. Spengler JR, Bente DA. Crimean-Congo hemorrhagic fever in Spain: new arrival or silent resident? N Engl J Med. 2017; 377:106-8. http://dx.doi.org/10.1056/NEJMp1707436

35. Filipe AR, Calisher CH, Lazuick J. Antibodies to Congo-Crimean hemorrhagic fever, Dhori, Thogoto and Bhanja viruses in southern Portugal. Acta Virol. 1985;29:324-8.

36. Palomar AM, Portillo A, Santibáñez S, García-Álvarez L, Muñoz-Sanz A, Márquez FJ, et al. Molecular (ticks) and serological (humans) study of Crimean-Congo hemorrhagic fever virus in the Iberian Peninsula, 2013-2015. Enferm Infecc Microbiol Clin. 2017;35:344-7. http://dx.doi.org/10.1016/j.eimc.2017.01.009

37. Lindeborg M, Barboutis C, Ehrenborg C, Fransson T, Jaenson TG, Lindgren PE, et al. Migratory birds, ticks, and Crimean-Congo hemorrhagic fever virus. Emerg Infect Dis. 2012;18:2095-7. http://dx.doi.org/10.3201/eid1812.120718

38. Palomar AM, Portillo A, Santibáñez P, Mazuelas D, Arizaga J, Crespo A, et al. Crimean-Congo hemorrhagic fever virus in ticks from migratory birds, Morocco. Emerg Infect Dis. 2013;19:260-3. http://dx.doi.org/10.3201/eid1902.121193

39. Vanhomwegen J, Alves MJ, Zupanc TA, Bino S, Chinikar S, Karlberg H, et al. Diagnostic assays for Crimean-Congo hemorrhagic fever. Emerg Infect Dis. 2012;18:1958-65. http://dx.doi.org/10.3201/eid1812.120710

Address for correspondence: Ana Negredo, National Center of Microbiology, Arbovirus and Imported Viral Diseases Laboratory, Crta. Majadahonda-Pozuelo Km 2, 28220 Majadahonda, Madrid, Spain; email: anabelnegredo@isciii.es 